American Journal of Pharmacology and Toxicology 7 (1): 1-7, 2012

ISSN 1557-4962

(C) 2012 Science Publications

\title{
Electroanalytical Determination of Doripenem using a Screen-Printed Electrode
}

\author{
Nora H. Al-Shaalan \\ Department of Chemistry, College of Science, \\ Princess Nora Bint Abdul Rahman University, Riyadh, Saudi Arabia
}

\begin{abstract}
Problem statement: The performance characteristics of Sensitive Screen-Printed (SPE) and Carbon Paste (CPE) electrodes were investigated for the Determination of Doripenem (DP) in pure, pharmaceutical preparations and biological fluids. Approach: The proposed electrodes is characterized in terms of plasticizer type, response time, $\mathrm{pH}$ and temperature. Results: The two electrodes showed nearly Nernstian behaviours over the concentration range of $2 \times 10^{-4}-5 \times 10^{-2} \mathrm{~mol} / \mathrm{l}$ of the drug with slopes of 58 and $57 \mathrm{mV} /$ decade for SPE and CPE electrodes, respectively. The electrodes exhibited good selectivity for DP with respect to a large number of inorganic cations and organic substances present in the biological fluids. The method was precise, as shown by the mean recoveries of 99.49-100 and 98.49-99.49\% with mean relative standard deviations $0.38-0.78$ and $0.60-0.90 \%$ for SPE and CPE electrodes, respectively. Conclusion: Doripenem was determined successfully in pure solutions, in vials or in biological fluids using the standard addition and potentiometric titration methods.
\end{abstract}

Key words: Screen-printed electrode, potentiometric titration, doripenem, biological fluids

\section{INTRODUCTION}

Doripenem (DP) (S-4661) (Fig. 1) is a recently developed member of the carbapenem class of betalactam antibiotics. Similarly to meropenem and ertapenem, but unlike imipenem, doripenem has a 1- $\beta$ methyl side chain that provides resistance to the renal enzyme I-dehydropeptidase. It was approved by the US Food and Drug Administration (FDA) in 2007 for the management of patients with complicated intraabdominal infections (dAIs) and complicated Urinary Tract Infections (cUTIs), including pyelonephritis (Mori et al., 1996). DP has been shown to have broadspectrum activity against Gram-negative and Grampositive pathogens, including strains of Pseudomonas aeruginosa (Jones et al., 2005; Wexler et al., 2005). DP, similar to other carbapenems, was developed for the treatment of hospitalised patients with moderate or severe bacterial infections (Jones et al., 2004)

Doripenem has been determined in its pharmaceutical formulation and in plasma using different techniques, including spectrophotometry (Piontek and Ska, 2010) chromatography High Performance Liquid Chromatography (HPLC) with various detection methods (Sutherland and Nicolau, 2007; Ikeda et al., 2008) and liquid chromatography (Dailly et al., 2011; Ohmori et al., 2011). The development and application of ion-selective electrodes for pharmaceutical analysis continue to be of interest because these sensors offer the advantage of simple design and operation, reasonable selectivity, fast response, applicability to coloured and turbid solutions and possible interface with automated and computerised systems (Santini et al., 2008). For these advantages, ISEs have found various applications: in clinical chemistry, environmental protection, water, soil and analytical chemistry in general (Kormosh et al., 2008).

Over the past five decades, carbon paste (i.e., a mixture of carbon (graphite) powder and a binder (pasting liquid)) has become one of the most popular electrode materials used for the laboratory preparation of various electrodes, sensors and detectors. Chemically Modified Carbon Paste Electrodes (CMCPEs) possess important advantages, such as ease of preparation, or regeneration and very stable response in addition to very low Ohmic resistance (Svancara et al., 2009). Therefore, CMCPEs have found direct application in a variety of analytical situations, such as amperometry (Ozoemena et al., 2004; Malongo et al., 2008), voltammetry (Mashhadizadeh and Akbarian, 2009) and potentiometry (Mostafa and Homoda, 2008).

In this study, we introduced new potentiometric sensors for selective determination of DP in pharmaceutical preparations and biological fluids. The present study describes the preparation, characterisation and application of Carbon Paste (CPE) and ScreenPrinted (SPE) electrodes for the continuous determination of DP in pharmaceutical preparations. 
Am. J. Pharm. \& Toxicol., 7 (1): 1-7, 2012

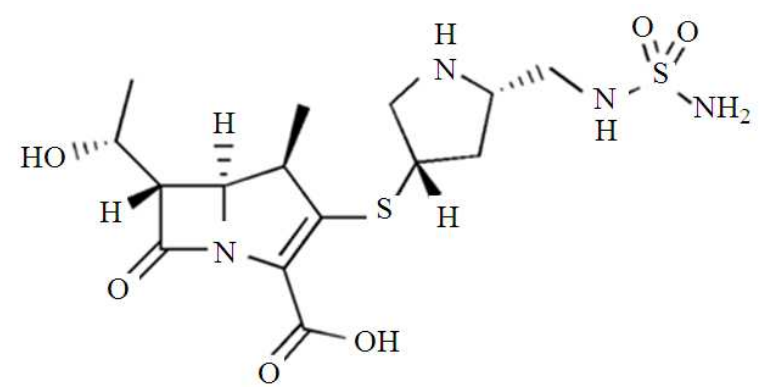

Fig. 1: The chemical structure of doripenem

The method described here is based on the ion-pair formation between doripenem and sodium tetraphenyl borate as electroactive materials and Tricresyl Phosphate (TCP) as a placticiser in the doripenem matrix. These sensors exhibited analytical characteristics with near-Nernstian sensitivity and low detection limit and were therefore useful as indicator electrodes in potentiometric titrations of doripenem in pure form, in vials, in urine and in serum samples.

\section{MATERIALS AND METHODS}

Apparatus: The potential measurements were performed using an Orion model $378 \mathrm{~A}$ instrument. A digital $\mathrm{pH} / \mathrm{mV}$ meter with a $\mathrm{Ag}-\mathrm{AgCl}$ saturated reference electrode was used for the measurements of potential differences at $25.0 \pm 1.0^{\circ} \mathrm{C}$. Elemental analysis was performed using a Vario E1 CHNOS Analyser.

Reagents and materials: All Chemicals were of analytical reagent grade. Double-distilled water was used to prepare all the experimental solutions. Doripenem was provided by Merck, Sharp and Dohme. Relatively high molecular weight polyvinyl chloride (PVC), graphite powder (synthetic 1-2 $\mu \mathrm{m}$ ) and Cellulose Acetate (CA) were purchased from Fluka. $o$ Nitrophenyloctylether (o-NPOE), Dibutylphthalate (DBP), Dioctylphthalate (DOP), Dioctylsebacate (DOS), Tricresylphosphate (TCP), sodium Tetraphenylborate (TPB) and Tetrahydrofuran (THF) were obtained from Sigma-Aldrich. Sodium phosphotungstate (Na-ph) and ammonium reineckate were obtained from Fluka.

Phosphate buffer was prepared by mixing aqueous solutions of $0.1 \mathrm{M}$ sodium dihydrogenphosphate and $0.1 \mathrm{M}$ disodium hydrogenphosphate to achieve solutions at the required $\mathrm{pH}$ values.

Pharmaceutical preparations: The contents of 10 ampoules were mixed. Accurately measured aliquots of the injection solution equivalent to $50 \mathrm{mg} / 2 \mathrm{~mL}$ of doripenem were analysed by the proposed electrodes.
Preparation of Carbon Paste Electrode sensor (CPE): CPE was prepared by mixing $(500 \mathrm{mg})$ highly pure graphite powder and plasticiser $(0.2 \mathrm{~mL}$ of $o$ NPOE, DOP, TCP, DBP and DOS). After mixing this matrix, the resulting paste was used to fill the electrode body. A fresh surface was obtained by gently pushing the stainless steel screw forward and polishing the new carbon paste surface with filter paper to obtain a shiny new surface (Frag et al., 2011).

Preparation of the screen-printed and carbon paste electrodes: SPEs were printed in arrays of six couples consisting of the indicator and the reference electrodes (each $5 \times 35 \mathrm{~mm}$ ). A flexible polyvinylchloride sheet $(0.2 \mathrm{~mm})$, which was not affected by the curing temperature or the ink solvent and easily cut by scissors, was used as the substrate. A pseudo $\mathrm{Ag}-\mathrm{AgCl}$ electrode was first printed using a homemade polyvinyl chloride ink containing silver/silver chloride (65:35) and cured at $60^{\circ} \mathrm{C}$ for $30 \mathrm{~min}$. The indicator electrodes were prepared depending on the method of fabrication. The indicator electrode was printed using homemade carbon ink (prepared by mixing $200 \mathrm{mg}$ DOS, $0.55 \mathrm{~g}$ of polyvinyl chloride (8\%) and $0.4 \mathrm{~g}$ carbon powder) and cured at $50^{\circ} \mathrm{C}$ for $30 \mathrm{~min}$. A layer of insulator was then placed on the printed electrodes, leaving a defined rectangularly shaped $(5 \times 5 \mathrm{~mm})$ working area with a similar area (for electrical contact) on the other side. Three types of the indicator electrodes were prepared depending on the method of fabrication. The fabricated electrodes were stored at $4^{\circ} \mathrm{C}$ and used directly for the potentiometric measurements (Khaled et al., 2008; Mohamed et al., 2010a; 2010b).

Potentiometric determination of DP: Doripenem was determined potentiometrically using the prepared electrodes by the standard addition method. Small increments of $10^{-3} \mathrm{~mol} / \mathrm{L}$ standard DP solution were added to $50 \mathrm{ml}$ aliquot of samples of various DP concentrations. The change in the cell potential due to the increase in DP concentration was recorded and used to calculate the concentration of DP in the sample solution.

Potentiometric titration of DP: An aliquot of DP solution was pipetted into a $100 \mathrm{~mL}$ titration vessel and the solution was diluted to $50 \mathrm{~mL}$ with double-distilled water. The resulting solution was titrated with $10^{-2}$ $\mathrm{mol} / \mathrm{l} \mathrm{NaTPB}$ solution and the change in cell potential upon addition of NaTPB was recorded. The volume of the titrant at the end point was recorded.

Determination of DP in biological fluids: Five millilitres of plasma or urine were collected from 
healthy persons and different amounts of DP (1.72$5.17 \mathrm{mg}$ ) were added. The resulting solutions were diluted to $50 \mathrm{~mL}$ with double-distilled water and subjected to potentiometric analysis using the proposed electrodes.

\section{RESULTS}

Elemental analysis: The elemental analysis of the formed doripenem-TPB ion pair was performed and the results were determined to be $\% \mathrm{C}=53.38, \% \mathrm{H}=$ $4.95, \% \mathrm{~N}=16.14$ and $\% \mathrm{~S}=21.50$, while the expected values were $\% \mathrm{C}=54.62, \% \mathrm{H}=5.04, \% \mathrm{~N}=$ 16.32 and $\% \mathrm{~S}=21.34$.

\section{Analytical parameters}

Electrode response: Five different plasticisers (DBP, $o$-NPOE, DOP, DOS and TCP) were considered in the selective membrane preparation. The plasticiser content was $70 \%$ of the total mass of the membrane components and the ionic strength of the solution was adjusted with $0.1 \mathrm{M} \mathrm{NaCl}$ solution. The influence of solvent mediators on the potentiometric response characteristics of the doripenem ion-selective electrode are summarised in Table 1. The best characteristics for the determination of doripenem were exhibited by the membranes plasticised with $o-\mathrm{NPOE}$ or TCP, with slope values of 55 and $58 \mathrm{mV} / \mathrm{pC}$, for SPE and 54 and $57 \mathrm{mV} / \mathrm{pC}$ for CPE, respectively.

Effect of plasticizer: The nature of the plasticiser (based on its polarity $\boldsymbol{\varepsilon}$ ) did not affect the sensitivity of the detection of the investigated ions but did significantly contribute to the value of the electrode function slope. The effect of the plasticiser itself on the electrode function slope, its linearity and the detection limit was then investigated. The ratio of plasticiser to the added PVC in the membrane was varied from $1: 1$ to a $2: 1$. The optimal component ratio was found to be 1.0 plasticiser to $1.0 \mathrm{PVC}$, as a membrane of sufficient elasticity and homogeneity could not be produced at any other ratio.

The effect of plasticiser content on the electrochemical characteristics of selective electrodes is illustrated in Table 2. No cation or mixed electrode function dependence on the polymer:plasticizer ratio was found; therefore, the matrix did not affect the selectivity of the film membranes. This assumption was indirectly corroborated by the similar values obtained for the electrode parameters of the ISEs (linearity of the electrode function and detection limits) as the PVC:plasticiser ratio increased.

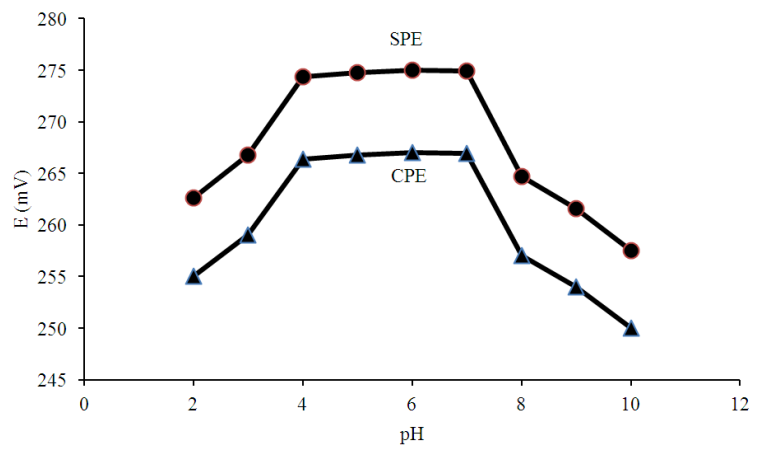

Fig. 2: Effect of $\mathrm{pH}$ using $0.01 \mathrm{~mol} / \mathrm{l} \mathrm{SPE}$ and 0.01 $\mathrm{mol} / \mathrm{l} \mathrm{CPE}$

Effect of pH: The $\mathrm{pH}$ dependence for a $10^{-3} \mathrm{M}$ doripenem solution is shown in (Fig. 2). The $\mathrm{pH}$ value had a negligible effect within the $\mathrm{pH}$ range of 4-7 and thus, the electrode could be used safety for DP determination within this range. At $\mathrm{pH}$ values higher than 7, the DP base precipitated and consequently the concentration of the protonated species decreased. As a result, lower e.m.f. readings were recorded. It was also clear from the obtained $\mathrm{pH}$ profile that the region of $\mathrm{pH}$ independence was mildly concentration- dependent and the potential did not fluctuate by more than $2 \mathrm{mV}$ in this region ( $\mathrm{pH} 4-7)$.

Selectivity: Selectivity is clearly one of the most important characteristics of an SPE sensor in which reliable measurement of the target drug is required. The selectivity coefficients ( $\log \mathrm{K}_{\mathrm{D}, \mathrm{B}}^{\mathrm{pot}}$ ) of the SPE and CPE were determined employing Separate Solution Methods (SSM) with a rearranged Nicolsky equation (Hassan et al., 1997):

$\log K_{D, B}^{\text {pot }}=\frac{E_{1}-E_{2}}{S}+\left(1+\frac{Z_{1}}{Z_{2}}\right) \log \alpha$

where, $\mathrm{E}_{1}$ is the potential measured in $1.0 \times 10^{-3} \mathrm{~mol} / 1$ DP (D), $E_{2}$ the potential measured in $1.0 \times 10^{-3} \mathrm{~mol} / \mathrm{l}$ of the interfering compound $(\mathrm{B}), \mathrm{z}_{1}$ and $\mathrm{z}_{2}$ are the charges of the DP (D) and interfering species (B), respectively and $\mathrm{S}$ is the slope of the electrode calibration plot. The results obtained are summarised in Table 3. A reasonable selectivity towards DP in the presence of many carbohydrates and nitrogenous compounds was observed. The results also showed no significant interference from a number of pharmaceutical excipients, diluents and active ingredients commonly used in drug formulations at concentrations as high as a 10-100-fold molar excess over DP. 
Am. J. Pharm. \& Toxicol., 7 (1): 1-7, 2012

Table 1: Response characteristics of DP- sensitive electrodes plasticised by different solvents

\begin{tabular}{|c|c|c|c|c|c|c|c|c|}
\hline \multirow[b]{2}{*}{$\begin{array}{l}\text { Pasticizer } \\
70 \%\end{array}$} & \multicolumn{4}{|l|}{ SPE } & \multicolumn{4}{|l|}{$\mathrm{CPE}$} \\
\hline & $\begin{array}{l}\text { Slope } \\
(\mathrm{mV} / \mathrm{pC})\end{array}$ & $\begin{array}{l}\text { Linearity } \\
\text { range }(\mathrm{mol} / \mathrm{l})\end{array}$ & $\begin{array}{l}\text { Detection } \\
\text { limit }(\mathrm{mol} / \mathrm{l})\end{array}$ & $\begin{array}{l}\text { Respnse } \\
\text { time (sec) }\end{array}$ & $\begin{array}{l}\text { Slope } \\
(\mathrm{mV} / \mathrm{pC})\end{array}$ & $\begin{array}{l}\text { Linearity } \\
\text { range (mol/l) }\end{array}$ & $\begin{array}{l}\text { Detection } \\
\text { limit, }(\mathrm{mol} / \mathrm{l})\end{array}$ & $\begin{array}{l}\text { Respnse } \\
\text { time }(\mathrm{sec})\end{array}$ \\
\hline o-NPOE & $55 \pm 2$ & $1 \times 10^{-4}-5 \times 10^{-2}$ & $6.5 \times 10^{-6}$ & 10 & $54 \pm 2$ & $1 \times 10^{-4}-5 \times 10^{-2}$ & $6.0 \times 10^{-6}$ & 9 \\
\hline TCP & $58 \pm 1$ & $2 \times 10^{-4}-5 \times 10^{-2}$ & $7.0 \times 10^{-6}$ & 5 & $57 \pm 2$ & $1 \times 10^{-4}-5 \times 10^{-2}$ & $7.3 \times 10^{-6}$ & 7 \\
\hline DBP & $52 \pm 1$ & $2 \times 10^{-4}-5 \times 10^{-2}$ & $6.0 \times 10^{-6}$ & 8 & $50 \pm 1$ & $1 \times 10^{-4}-5 \times 10^{-2}$ & $5.5 \times 10^{-6}$ & 15 \\
\hline DOS & $47 \pm 2$ & $3 \times 10^{-4}-5 \times 10^{-2}$ & $5.5 \times 10^{-6}$ & 15 & $49 \pm 1$ & $2 \times 10^{-4}-5 \times 10^{-2}$ & $5.5 \times 10^{-6}$ & 15 \\
\hline DOP & $54 \pm 1$ & $2 \times 10^{-4}-5 \times 10^{-2}$ & $6.2 \times 10^{-6}$ & 10 & $52 \pm 2$ & $2 \times 10^{-4}-5 \times 10^{-2}$ & $6.0 \times 10^{-6}$ & 20 \\
\hline
\end{tabular}

Table 2: The effect of plasticiser content on the electrochemical characteristics of a DP-sensitive electrode

\begin{tabular}{|c|c|c|c|c|c|c|c|c|c|c|}
\hline \multirow[b]{2}{*}{$\begin{array}{l}\text { Content } \\
\text { of TCP } \\
(\%)\end{array}$} & \multicolumn{5}{|l|}{ SPE } & \multicolumn{5}{|l|}{$\mathrm{CPE}$} \\
\hline & $\begin{array}{l}\text { Slope } \\
(\mathrm{mV} / \mathrm{pC})\end{array}$ & $\begin{array}{l}\text { Linearity } \\
\text { range } \\
(\mathrm{mol} / \mathrm{l})\end{array}$ & $\begin{array}{l}\text { Detection } \\
\text { limit } \\
(\mathrm{mol} / \mathrm{l})\end{array}$ & $\begin{array}{l}\text { Respnse } \\
\text { time (sec) }\end{array}$ & $\begin{array}{l}\text { Lifetime } \\
\text { (day) }\end{array}$ & $\begin{array}{l}\text { Slope } \\
(\mathrm{mV} / \mathrm{pC})\end{array}$ & $\begin{array}{l}\text { Linearity } \\
\text { range } \\
(\mathrm{mol} / \mathrm{l})\end{array}$ & $\begin{array}{l}\text { Detection } \\
\text { limit } \\
(\mathrm{mol} / \mathrm{l})\end{array}$ & $\begin{array}{l}\text { Respnse } \\
\text { time (sec) }\end{array}$ & $\begin{array}{l}\text { Lifetime } \\
\text { (day) }\end{array}$ \\
\hline 70 & $58 \pm 1$ & $2 \times 10^{-4}-5 \times 10^{-2}$ & $6.5 \times 10^{-6}$ & 5 & 31 & $57 \pm 2$ & $1 \times 10^{-4}-5 \times 10^{-2}$ & $7.0 \times 10^{-6}$ & 8 & 30 \\
\hline 60 & $55 \pm 2$ & $2 \times 10^{-4}-5 \times 10^{-2}$ & $6.0 \times 10^{-6}$ & 8 & 30 & $53 \pm 2$ & $1 \times 10^{-4}-5 \times 10^{-2}$ & $6.6 \times 10^{-6}$ & 10 & 30 \\
\hline 50 & $52 \pm 1$ & $2 \times 10^{-4}-5 \times 10^{-2}$ & $6.0 \times 10^{-6}$ & 8 & 25 & $50 \pm 1$ & $1 \times 10^{-4}-5 \times 10^{-2}$ & $6.2 \times 10^{-6}$ & 10 & 27 \\
\hline 40 & $49 \pm 1$ & $2 \times 10^{-4}-5 \times 10^{-2}$ & $5.8 \times 10^{-6}$ & 10 & 25 & $46 \pm 2$ & $1 \times 10^{-4}-5 \times 10^{-2}$ & $5.7 \times 10^{-6}$ & 15 & 25 \\
\hline 30 & $46 \pm 2$ & $2 \times 10^{-4}-5 \times 10^{-2}$ & $5.5 \times 10^{-6}$ & 10 & 21 & $45 \pm 1$ & $1 \times 10^{-4}-5 \times 10^{-2}$ & $5.5 \times 10^{-6}$ & 15 & 20 \\
\hline
\end{tabular}

Analytical applications: The electrodes were demonstrated to be useful in the potentiometric determination of DP in pure solutions by both the standard addition and the potentiometric titration methods. The collective results are shown in Table 4. Five replicate determinations at different concentration levels were performed using the two studied electrodes to test the precision of the method. The standard deviations were found to be $\leq 1.0$, indicating reasonable repeatability and reproducibility of the selected method.

The proposed potentiometric method was applied to the determination of DP in biological fluids, such as human serum and urine. The results obtained are summarised in Table 5. The accuracy of the proposed SPE and CPE sensors was investigated through the determination of DP in doripenem monohydrate samples prepared from serial concentrations of DP reference standards. The results summarised in Table 5 show that the proposed potentiometric method was accurate for the determination of DP in urine and serum samples without interference from the coformulated adjuvants.

Effect of temperature: Thermal stability of the electrodes was tested by constructing calibration graphs for the electrode potential, $\mathrm{E}_{\text {elect, }}$ versus $\mathrm{pDP}$ at temperatures covering ranging from $10-60^{\circ} \mathrm{C}$. The electrode potentials from these graphs at $\mathrm{pDP}=0$ were obtained and plotted versus (T-25), where $\mathrm{T}$ was the temperature of the solution. A straight line was obtained for the electrode, the slope of which $(\mathrm{dE} / \mathrm{dT})$ represented the thermal coefficient of the electrode (Arvand et al., 2008).
Table 3:Potnetiometric selectivity coefficient of SPE and CPE plasticised with TCP

\begin{tabular}{lll}
\hline & \multicolumn{1}{c}{$\mathrm{K}_{\mathrm{D}, \mathrm{B}}^{\mathrm{pot}}$} & \\
\hline Interferent & $\mathrm{SPE}$ & $\mathrm{CPE}$ \\
\hline $\mathrm{Na}^{+}$ & $1.0 \times 10^{-6}$ & $1.2 \times 10^{-5}$ \\
$\mathrm{NH}_{4}{ }^{+}$ & $1.9 \times 10^{-6}$ & $3.6 \times 10^{-4}$ \\
$\mathrm{~K}^{+}$ & $0.8 \times 10^{-5}$ & $1.6 \times 10^{-6}$ \\
$\mathrm{Fe}^{3+}$ & $1.7 \times 10^{-6}$ & $7.8 \times 10^{-5}$ \\
$\mathrm{Ca}^{2+}$ & $2.3 \times 10^{-4}$ & $7.3 \times 10^{-5}$ \\
Sucrose & $4.0 \times 10^{-6}$ & $3.1 \times 10^{-5}$ \\
Glucose & $6.5 \times 10^{-6}$ & $5.1 \times 10^{-6}$ \\
Lactose & $1.1 \times 10^{-6}$ & $6.3 \times 10^{-6}$ \\
Maltose & $6.4 \times 10^{-6}$ & $4.5 \times 10^{-5}$ \\
Glycine & $3.8 \times 10^{-5}$ & $6.5 \times 10^{-5}$ \\
Alanine & $8.1 \times 10^{-5}$ & $3.5 \times 10^{-6}$ \\
Starch & $5.2 \times 10^{-5}$ & $4.5 \times 10^{-5}$ \\
Dextrose & $5.7 \times 10^{-4}$ & $6.0 \times 10^{-6}$ \\
Ascorbic acid & $1.3 \times 10^{-5}$ & $5.510^{-5}$ \\
\hline
\end{tabular}

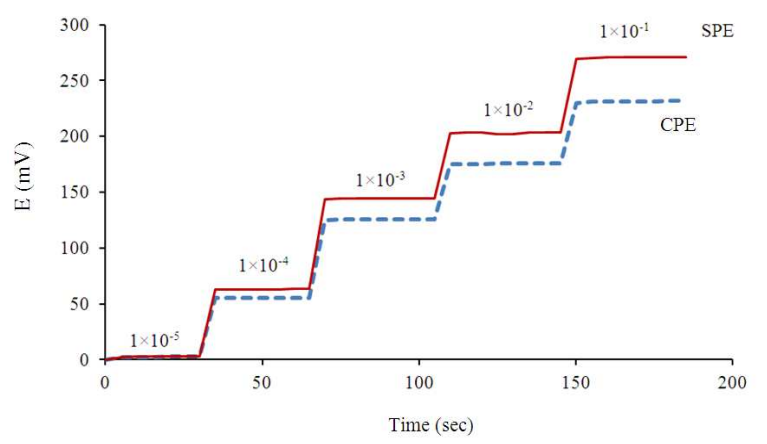

Fig. 3: Dynamic responses of different DP sensors: (a) $1 \times 10-5$, (b) $1 \times 10-4$, (c) $1 \times 10-3$, (d) $1 \times 10-2$ and (e) $1 \times 10-1 \mathrm{~mol} / \mathrm{l} \mathrm{DP}$ 
Am. J. Pharm. \& Toxicol., 7 (1): 1-7, 2012

Table 4: Precision of the standard addition and potentiometric determination methods on pure doripenem

\begin{tabular}{|c|c|c|c|c|c|c|c|}
\hline \multirow[b]{2}{*}{ Electrode } & \multirow[b]{2}{*}{ Taken $(\mathrm{mg} / \mathrm{L})$} & \multicolumn{3}{|c|}{ Standard addition } & \multicolumn{3}{|c|}{ Potentiometric titration } \\
\hline & & Found (mg/L) & Recovery (\%) & $\operatorname{RSD}^{\mathrm{a}}(\%)$ & Found $(\mathrm{mg} / \mathrm{L})$ & Recovery (\%) & $\operatorname{RSD}^{\mathrm{a}}(\%)$ \\
\hline$\overline{\mathrm{SPE}}$ & 19.9 & 19.8 & 99.49 & 0.78 & 19.9 & 100 & 0.38 \\
\hline CPE & 19.9 & 19.6 & 98.49 & 0.90 & 19.8 & 99.49 & 0.60 \\
\hline
\end{tabular}

${ }^{a}$ : Average of four dtermination

Table 5: Standard addition and potentiometric titration methods for the determination of doripenem in vials and in biological fluids

\begin{tabular}{llcc}
\hline Electrode & Sample & $\begin{array}{c}\text { Standard addition } \\
\text { Mean recovery } \pm \mathrm{SD}^{\mathrm{a}}\end{array}$ & $\begin{array}{c}\text { Potentiometric titration } \\
\text { Mean recovery } \pm \mathrm{SD}^{\mathrm{a}}\end{array}$ \\
\hline SPE & Vials (Doribax) & $100.1 \pm 0.8$ & $100.05 \pm 0.33$ \\
& Urine & $99.6 \pm 1.05$ & $99.88 \pm 0.67$ \\
& Plasma & $98.9 \pm 0.70$ & $99.67 \pm 0.88$ \\
$\mathrm{CPE}$ & Vials (Doribax) & $101 \pm 0.90$ & $100 \pm 0.41$ \\
& Urine & $100.6 \pm 0.84$ & $100.04 \pm 0.33$ \\
& Plasma & $99.78 \pm 0.34$ & $99.89 \pm 0.44$ \\
\hline
\end{tabular}

${ }^{\mathrm{a}} ;$ Mean \pm standard deviation of five determinations

Response time: The response time was recorded by increasing the DP (I) ion concentration in solution from $1.0 \times 10^{-5}$ to $1.0 \times 10^{-1} \mathrm{M}$, with subsequent measurement of the corresponding stable potentials. To evaluate the reversibility of the electrode, a similar procedure in the opposite direction was adopted with measurements performed in the sequence of high-to-low sample concentration. The results, depicted in Fig. 3, showed that the response times of the fabricated SPE and CPE were 5 and $7 \mathrm{~s}$, respectively.

Selectivity: The mechanism of selectivity is primarily based on the stereo specificity and electrostatic environment and is dependent on how much matching is present between the location of the lipophilic sites in the two competing species in the bathing solution side and those present in the receptor of the ion exchanger. The inorganic cations did not interfere due to the differences in ionic size and, consequently, in their mobilities and permeabilities. Additionally, the smaller the energy of hydration of the cation, the greater the response of the membrane. In the case of sugars and amino acids, the high selectivity was primarily attributed to the difference in polarity and lipophilic character of their molecules relative to DP.

Although there are many restrictions that must be taken into consideration when using the separate solution method (Antropov, 2001) to determinate of selectivity coefficients, especially in the case of mixed ion solutions of different charges, this method is still the simplest way to demonstrate interference. In pharmaceutical analysis, it is important to test selectivity towards excipients and fillers added to pharmaceutical preparations. Fortunately, such materials often do not interfere, which was evident from the results obtained for the pharmaceutical preparations (Table 3). Therefore, the sensors were found to be chemically inert to other substances in a matrix of interest.

\section{DISCUSSION}

Analytical parameters: The plasticiser content is related to the lifetime of the electrode, which is determined by the frequency of its use. It was established that electrodes with lower plasticiser content lasted for a shorter time than those with higher plasticiser content. The solvent content in the membrane decreased with time, which led to structure failure and loss of elasticity and limiting the electrode's lifetime. We perused the literature (Kormosh et al., 2009) to investigate the change in the electrode characteristics of prepared doripenem-selective electrodes over time and found that membrane stability was checked at intervals. Sensors with $60-70 \%$ plasticiser content had a shelf life of 31 days, unlike sensors with a lower (30-50\%) plasticiser content (Kormosh et al., 2010).

Effect of pH: The decrease in $\mathrm{mV}$ readings at $\mathrm{pH}<4$ may have been due to interference from hydronium ions. At higher $\mathrm{pH}$ values $(\mathrm{pH}>7.0)$, free base precipitated in the test solution and the concentration of unprotonated species gradually increased (Frag et al., 2011). As a result, lower e.m.f. readings were recorded. Therefore, a $\mathrm{pH}$ value of 5 was recommended for subsequent studies.

Effect of temperature: The slope was found to be $0.0001 \mathrm{~V} /{ }^{\circ} \mathrm{C}$. This indicated fairly high thermal stability for the electrodes within the investigated temperature range and showed no deviation from the theoretical Nernstian behaviour.

\section{CONCLUSION}

In the present study, a carbon-paste electrode was used for the simultaneous determination of DP in vials together with SPE. The CPE and SPE investigations showed effective electrocatalytic activity in determining DP in pure and pharmaceutical formulations. High sensitivity and selectivity, very low detection limit, ease of preparation, surface 
regeneration of the electrode and reproducibility of the electrodes responses made the proposed electrodes very useful for the accurate determination of DP in pharmaceutical preparations.

\section{REFERENCES}

Antropov, L.I., 2001. Theoretical Electrochemistry. 1st Edn., Honolulu University Press of the Pacific, ISBN: 0898753236, pp: 572.

Arvand, M., M. Vejdani and M. Moghimi, 2008. Construction and performance characterization of an ion selective electrode for potentiometric determination of atenolol in pharmaceutical preparations. Desalination, 225: 176-184. DOI: 10.1016/j.desal.2007.06.017

Dailly, E., R. Bouquie, G. Deslandes, P. Jolliet and R. Le Floch, 2011. A liquid chromatography assay for a quantification of doripenem, ertapenem, imipenem, meropenem concentrations in human plasma: Application to a clinical pharmacokinetic study. J. Chromatography B., 879: 1137-1142. DOI: $10.1016 /$ j.jchromb.2011.03.038

Frag, E.Y.Z., G.G. Mohamed and W.G. El-Sayed, 2011. Potentiometric determination of antihistaminic diphenhydramine hydrochloride in pharmaceutical preparations and biological fluids using screen-printed electrode. Bioelectrochemistry, $\quad 82$ : 79-86. DOI: 10.1016/j.bioelechem.2011.05.006

Hassan, S.S.M., W.H. Mahmoud and A.M. Othman, 1997. A novel potassium ion membrane sensor based on rifamycin neutral ionophore. Talanta, 44: 1087-1094. DOI: 10.1016/S0039-9140(96)02199-6

Ikeda, K., K. Ikawa, N. Morikawa, K. Kameda and N. Urakawa et al., 2008. Quantification of doripenem in human plasma and peritoneal fluid by highperformance liquid chromatography with ultraviolet detection. J. Chromatography B., 867: 20-25. DOI: 10.1016/j.jchromb.2008.03.001

Jones, R.N., H.K. Huynh and D.J. Biedenbach, 2004. Activities of doripenem (S-4661) against drugresistant clinical pathogens. Antimicrob. Agents Chemother, 48: 3136-3140. DOI: 10.1128/AAC.48.8.3136-3140.2004

Jones, R.N., H.S. Sader and T.H. Fritsche, 2005. Comparative activity of doripenem and three other carbapenems tested against Gram-negative bacilli with various $\beta$-lactamase resistance mechanisms. Diagn. Microbiol. Infect. Dis., 52: 71-74. DOI: 10.1016/j.diagmicrobio.2004.12.008
Khaled, E., G.G. Mohamed and T. Awad, 2008. Disposal screen-printed carbon paste electrodes for the potentiometric titration of surfactants. Sens. Actuators, $\quad$ B., $\quad 135$ : 74-80. DOI: 10.1016/j.snb.2008.07.027

Kormosh, Z., I. Hunka and Y. Bazel, 2008. An electrode immobilized in a graphite matrix with ion pair complex for the determination of diclofenac in pharmaceuticals. J. Iran. Chem. Res., 1: 25-32.

Kormosh, Z., I. Hunka and Y. Bazel, 2009. Potentiometric sensor for the indomethacin determination. Mat. Sci. Eng., C 3: 1018. DOI: 10.1016/j.msec.2008.09.003

Kormosh, Z., I. Hunka, Y. Bazel and O. Matviychuk, 2010. Potentiometric determination of ketoprofen and piroxicam at a new PVC electrode based on ion associates of Rhodamine 6G. Mat. Sci. Eng.: C., 30: 997-1002. DOI: 10.1016/j.msec.2010.04.015

Malongo, T.K., S. Patris, P. Macours, F. Cotton and J. Nsangu et al., 2008. Highly sensitive determination of iodide by ion chromatography with amperometric detection at a silver-based carbon paste electrode. Talanta, 76: 540-547. DOI: 10.1016/j.talanta.2008.03.053

Mashhadizadeh, M.H. and M. Akbarian, 2009. Voltammetric determination of some antimalarial drugs using a carbon paste electrode modified with $\mathrm{Cu}(\mathrm{OH}) 2$ nanowire. Talanta, 78: 1440-1445. DOI: 10.1016/j.talanta.2009.02.040

Mohamed, G.G., T.A. Ali, M.F. El-Shahat, A.M. AlSabagh and M.A. Migahed et al., 2010a. Potentiometric determination of cetylpyridinium chloride using a new type of screen-printed ion selective electrodes. Anal. Chim. Acta, 673: 79-87. DOI: $10.1016 / j$.aca.2010.05.016

Mohamed, G.G., T.A. Ali, M.F. El-Shahat, A.M. AlSabagh and M.A. Migahed, 2010b. New screenprinted ion-selective electrodes for potentiometric titration of cetyltrimethyl ammonium bromide in different civilic media. Electroanalysis, 22: 25872599. DOI: 10.1002/elan.201000096

Mori, M., M. Hikida, T. Nishihara, T. Nasu and S. Mitsuhashi, 1996. Comparative stability of carbapenem and penem antibiotics to human recombinant dehydropeptidase I. J. Antimicrob. Chemother, 37: 1034-1036. DOI: 10.1093/jac/37.5.1034

Mostafa, G.A. and A.M. Homoda, 2008. Potentiometric carbon paste electrodes for the determination of bismuth in some pharmaceutical preparations. B. Chem. Soc. Jpn., 81: 257-261. DOI: $10.1246 /$ bcsj. 81.257 
Ohmori, T., A. Suzuki, T. Niwa, H. Ushikoshi and K. Shirai et al., 2011. Simultaneous determination of eight $\beta$-lactam antibiotics in human serum by liquid chromatography-tandem mass spectrometry. J. Chr. B, 879: 1038-1042. DOI: 10.1016/j.jchromb.2011.03.001

Ozoemena, K.I., R. Stefan and T. Nyokong, 2004. Determination of 2,3-dideoxyinosine using iron (II) phthalocyanine modified carbon paste electrode. Anal. Lett., 37: 2641-2648. DOI: 10.1081/AL200031940

Piontek, J. C. and A. J. Ska, 2010. The UV-derivative spectrophotometry for the determination of doripenem in the presence of its degradation products. Spectrochim. Acta Part A, 77: 554-557. DOI: $10.1016 /$ j.saa.2010.06.019

Santini, A.O., H.R. Pezza, J.E. De Oliveira and L. Pezza, 2008. Development of a potentiometric flufenamate ISE and its application to pharmaceutical and clinical analyses. J. Braz. Chem. Soc., 19: 162-168. DOI: 10.1590/S010350532008000100023
Sutherland, C. and D. P. Nicolau, 2007. Development of an HPLC method for the determination of doripenem in human and mouse serum. J. Chr., B 853: $\quad 123-126 . \quad$ DOI: 10.1016/j.jchromb.2007.03.004

Svancara, I., K. Vytras, K. Kalcher, A. Walcarius and J. Wang, 2009. Carbon paste electrodes in facts, numbers and notes: A review on the occasion of the 50-years jubilee of carbon paste in electrochemistry and electroanalysis. Electroanalysis, 21: 7-28. $\quad$ DOI: 10.1002/elan.200804340

Wexler, H.M., A.E. Engel, D. Glass and C. Li, 2005. In vitro Activities of doripenem and comparator agents against 364 anaerobic clinical isolates. Antimicrob. Agents Chemother, 49: 4413-4417. DOI: 10.1128/AAC.49.10.4413-4417.2005 